\title{
Finding common ground: Alternatives to code models for language use
}

\author{
Carol A. Fowler ${ }^{1}$ \\ and \\ Bert Hodges 1, 2 \\ ${ }^{1}$ University of Connecticut, Storrs, CT \\ ${ }^{2}$ Gordon College, Wenham, MA
}




\begin{abstract}
The papers in this special issue offer valuable perspectives on public language activities as they are embedded in cultural and social contexts. The perspectives are diverse in their theoretical perspectives, the issues on which they focus, and the methodologies they use and promote using. They represent language studies from the perspective of ecological psychology, dynamical systems approaches, the Distributed Language Approach, and others. The contributions are, in some cases, revolutionary and dis-equilibrating. Different contributions to the special issue offer critiques of conventional scientific studies of decontextualized language and language processing, and offer new perspectives on such diverse domains as the understanding of agency, the study of reading, educational practice, and understanding how articulatory speech actions can have significance beyond that of the physical actions themselves.
\end{abstract}


The papers in this special issue represent talks and posters given at a conference (Finding Common Ground: Social, Ecological and Cognitive Perspectives on Language Use) held at University of Connecticut in June, 2014. We chose contributions for this special issue that offer exciting and forward-looking perspectives for future explorations of language use.

Many participants in the conference, including contributors to this special issue, are revolutionaries, seeking to overthrow decades of entrenched ideas about language: that it is fundamentally a representational system for encoding ideas, that it is primarily a system for representing thought (e.g., Chomsky, 2011) and that, when it is used interpersonally, is a code system for transmitting meanings between people (Harris, 1981; Bickhard, 2009). The force of the research agendas represented at the conference is to move the study of language in a different direction, one in which language use (or "languaging," e.g., Maturana, 1988, 2000) is a public, whole-body activity that is integral with other sensemaking activities (e.g., gestures, facial expressions, eye gaze) and is fundamentally interpersonal, social, and embedded in the activities of everyday life. Its functions are many, but centrally, it is used in the service of shared goals of members of social groups.

For those of us whose encounters with language as an object of study have been primarily in the wake of the also-very-exciting Chomskyan revolution and in the subsequent development of cognitive science, including psycholinguistics, these new ideas are both exciting and dis-equilibrating. In the following, we provide brief overviews of the contributions to the special issue hoping both to underscore why the ideas are novel, exciting, even revolutionary, but also to provide some cautionary notes, to press lightly on the brakes, to suggest sometimes: But wait.... 


\section{Folk metalinguistic practice and the scientific study of language}

Talbot Taylor (this issue) notes that our "Western linguistic tradition" has identified ("deeply mesmerizing") entities and properties of language that serve as explananda for scientific studies of language. For example, utterances are said to be composed of words that have meanings and can refer to entities in the world. However, Taylor suggests that these entities and properties are, in fact, "folk linguistic fictions" that are decontextualized extractions from metalinguistic talk within Western cultures. However, metalinguistic talk is not general cross culturally and, in any case, its decontextualized components do not supply defensible scientific explananda.

Metalinguistic talk is the self-reflexive dimension of utterances that refer to language (e.g., [ikanamiks] and [Ekanamiks] are the same word) or to acts of speaking and listening (e.g., What's that called? Please don't lie to me. What do you mean?), which allow a speaker to comment on, to appeal to, to question, to sanction, to defend, to promise, or to tease another. A central question Taylor addresses is, what is the status of the metalinguistic practices in which humans engage? In a deeper sense, Taylor's question-itself a metalinguistic move- is directed to $u s$, that is, those who engage in scientific practice and study linguistic activity, who make claims about what people do when they speak and listen to each other.

How should scientists approach the study of language? According to Taylor, naturalistically-inclined researchers (as characterized e.g., by Kitchener, 2006) offer two approaches. One is the "scorched-earth" policy of "cognitive eliminativists" who claim that folk-psychological entities—everything from "words" and "the English 
language" to "meaning" and "understands" - are irrelevant to a properly naturalistic science. Not surprisingly, most find this too extreme and adopt a policy of trying to identify those entities and processes that are factual (e.g., that "carve nature at its joints") rather than fictitious (e.g., stellar constellations). However, agreement about such matters has proven elusive.

Taylor's approach to the problem is quite different. He argues that metalinguistic practice itself is at the heart of language and of cultural life. He presents a twin-earth thought experiment to show that without metalinguistic practice, what it means to be a competent speaker would be wholly transformed, as would "cultural forms of life." (For example, he remarks that there would be no way to enforce laws, translate between languages or plan for the future.) In addition, regarding the diversity of "linguistic-cultural practices across and within speech communities worldwide" and the "limitless range of linguistic referents ... having no privileged or universal status" (Taylor, this issue, p. 10 pre-pub. ms.), he concludes that language researchers would be wise to place these various "folk metalinguistic practices" at the center of investigation. That is, they should resist the seductive tendency to decontextualize them or to misrepresent them within the metalinguistic practices of the "Western linguistic imaginary" (p. 15). Finally, and most provocatively, Taylor proposes that naturalistic researchers have plenty of room to explore and explain, if they remember that linguistic questions have "all the explanations they require" in the "culturally-diverse, context-dependent, ... and embodied practices of everyday metalinguistic discourse" (p. 16). The answer to 
what he calls the "hard problem of language" is lived, not theorized. Or, rather it is theorized within a living, culturally situated metapragmatics.

It is tempting to read Taylor as postmodern, denying the legitimacy of science as usually practiced. Frankly, that is one of our reactions. We say: But wait. To experimental psychologists, Taylor's revolutionary comments are somewhat discouraging because they appear to render useless and wrong-headed the decades of experimental research on sentence production and comprehension, mental lexicons, speech perception and production and much, much more (but also see Wallot's contribution in this issue, discussed below). Moreover, we don't quite get how, within the context of a culture's metalinguistic practices, issues of word meaning, reference and understanding can have "all the explanation they need."

We pose some questions for discussion. Our first question is: Are not the metalinguistic practices within which Taylor wrote, and we read, and within which we are now writing, and he and others will read, part and parcel of the metalinguistic practices that he and others have named "scientific" and "naturalistic"? Other questions might be: (1) Is the claim that that there is a cross cultural diversity of metalinguistic practices intended to forbid any search for common ground (see Harvey and Cowley's contribution in this issue), universals, invariants, or common units of linguistic or metalinguistic analysis? (Is there nothing that warrants referring to the languages of the world jointly as "languages"?) (2) Relatedly, is it not important to address Taylor's "disagreements [that] need not detain us" (p.7) regarding which folk-linguistic entities might be legitimate to include in a naturalistic scientific approach to language? For example, 
cannot relevant cross-cultural studies of spontaneous errors of speech production (e.g., heft lemisphere, or the sky is in the sun); (errors from Dell, 1986) uncover natural, possibly universal, linguistic entities? Can cross-cultural findings from selective aphasias in which, say, nouns or verbs are selectively impaired (e.g., Raggi, Zonca, Pistarini, Contardi, \& Pinna, 2002) reveal possibly universal syntactic word properties? Or, are claims about "errors" and "selectivity" culture-and-contextdependent practices that are themselves open to evaluative debate and negotiation?

Perhaps, Taylor is not offering a challenge to scientific metalinguistic practices, but simply reminding his readers that, as scientists, they do not transcend cultures, contexts, and the responsibilities that are inherent in metalinguistic phenomena (cf. Ingold, 2000, chap. 1). If so, we agree. As we have put it elsewhere: "In the end our theories answer to our actual lived conversations, including the ones that are about language itself" (Hodges \& Fowler, 2015, p. 187).

\section{Language myths also contaminate educational practice}

The contributions by Taylor and Kravchenko are alike in addressing language mythologies that can drive important human activities in wrong directions. For Taylor the myth is that entities invoked in metalinguistic talk are real and can serve as appropriate objects of scientific study. For Kravchenko, the mythology reflects a misunderstanding both of written and spoken language that has guided educational practices to their detriment.

One component of the mythology is an idea that written and spoken languages are fundamentally the same thing; written language is speech written down. Another component is "the code fallacy," including fallacious ideas that language is independent of 
thought, is a tool for representing thought and for conveying the thoughts of one person to someone else, and is composed of a lexicon of words that are combined into sentences by rule.

According to Kravchenko, educational practice is guided by the code fallacy. Children are taught how to use writing to encode ideas by selecting words and sequencing them according to rules that they are required to learn. This serves to institutionalize the code fallacy, but it does not foster skillful languaging or functional literacy.

Educational practice would be quite different, according to Kravchenko, if educators had a realistic understanding of spoken and written language. Both shape cognitive abilities and sustain life in the econiche, but they do so in quite different ways. Canonically, speaking is an interactional, social activity that occurs on the fly and in concert with manual gesturing, facial expressions and more. For children, participation in languaging activities becomes a way to orient to the econiche, to acquire societal values, and generally to become integrated into human society. As for writing, it is a more introspective, offline individual skill that provides opportunities beyond those of languaging, for example, an opportunity to offload cognitive products onto material artefacts.

Kravchenko suggests that educators need to be disabused of the code fallacy and other fallacious ideas about language, and they should be given tools to foster effective dialogic interaction on the one hand, and effective use of writing on the other. These ideas are very exciting and, for the most part, compelling.

The "but wait" here is on three fronts. First, there is another difference between speaking and writing that should have some relevance to educational practice. It is that children pick up the spoken language on the fly, but rarely pick up literacy in that way. 
Therefore, it should be no surprise that educators devote far more time to honing written as contrasted with spoken language skills. The second thing is related. Writing systems are composed of units, say, letters for alphabetic systems, that are sequenced to form those words that, as noted above in the discussion of Taylor's paper, announce themselves as such in some spontaneous errors of speech perception and are separated by spaces in writing. ${ }^{1}$ Those words are sequenced in systematic ways so that words come to serve grammatical roles. To learn to use the written language, children have to learn the units and how to sequence them systematically according to conventional practice for that written language. This seems to be true whether or not the teacher buys into the code fallacy. The third front, then, is to remark that the paper does not tell us what teachers should substitute for what they do now. Kravchenko provides an "agenda," but one that specifies what educators should "realize," not what teachers should do.

\section{Maybe writing and languaging are not so different after all}

Wallot's (this issue) approach to the study of reading is truly revolutionary. Whereas Kravchenko's contribution focuses on some important differences between writing and talking, Wallot's focuses on apparent similarities between reading and conversation. Recognition of these similarities is likely to transform the study of reading by experimentalists. There is no contradiction between Kravchenko and Wallot, because the two researchers are attending to quite different matters. Kravchenko is attending to written language use as an enhancer of cognitive capabilities and to the educational implications of erroneous ideas about language. Wallot is addressing research (e.g., Frost, 2012; Rayner, Chace, Slattery, \& Ashby, 2006) on reading as a local set of performance

1 Were writing systems developed by people who bought into the code fallacy? 
skills. Much of this research has been on visual word recognition, a highly productive domain, but one that provides a very specific and special window on reading. Wallot's aim here is to argue that there is far more to reading than what these special studies have shown.

He suggests, convincingly, we judge, that there are variables, typically avoided in the study of word, sentence, and text reading that are studied and discussed by researchers who study conversational interactions and that have important analogues in the reading domain. In the domain of reading, these include variables such as the reader's intentions in attending to text, the author's intentions in writing it, and varieties of situational variables that can affect how readers extract meaning from the printed page.

Wallot documents research showing limits on the generality of findings from current research on reading. For example, he shows that the extent to which word properties (such as their frequency, their length, their numbers of similarly spelled neighbors in the language) have an effect on reading measures (e.g., times to decide whether a letter string is a word or not) can vary from being important in isolated word reading, to weak in sentence reading, to absent in text reading. In short, reading is not the same process over contexts, settings, and participant intentions.

These kinds of observation are momentous, because they indicate that findings from the extensive literature on isolated word recognition do not generalize to the more typical settings in which individuals encounter text outside the laboratory. For that matter, findings from any kind of reading task are unlikely to generalize easily to other reading tasks. These observations make the task of studying reading far more complex (and far more interesting) than it has seemed to be to date. 
Wallot suggests that researchers might benefit from Wittengstein's ideas (1953/2010) of "form of life" and "language game" as a way of discovering illuminating approaches to explorations of written language use. Form of life refers to historical, cultural and social constraints that define the kinds of language use that can emerge in particular settings. A language game is one such emergent usage. Usages have in common that they are rule-following, in exerting a structuring effect on reader behavior, but the rules do not generalize to different settings. Of course, a tricky task, then, is to figure out what the rules are in each case. He proposes approaches from dynamical systems analysis, such has recurrence quantification analysis (Webber \& Zbilut, 1994), that reveal, among other things, the amount of structure in measures, for example, measures of reader behavior. He and colleagues have found that measures of percent determinism (amount of structure) from this analysis provide a better predictor of reading skill and comprehension than do more conventional measures (e.g., mean reaction times to perform some reading task). This may be because, like natural reading itself, dynamical systems approaches are sensitive to the temporal dimension of behavior and its context..

We don't have a "but wait" reaction to this research. The work that Wallot is promoting is very, very challenging, but is likely to enrich the study of reading well beyond its current state and to help to embed the studying of reading within the larger context provided by the study of public language use more generally.

\section{The probatonic principle and Cognitive Event Analysis}

Steffensen (this issue) is not so revolutionary as to suggest overthrowing traditional experimental research. However, he prefers an alternative to traditional hypothesis-testing research for studying language use because it throws off the shackles of experimental 
constraints that can distort or destroy the phenomenon under study (as Wallot highlights in his discussion of reading research). The very restrictions that permit experimental research to provide replicable observations under controlled conditions and to provide fairly tight constraints on interpretation of findings also limit the generalizability of findings to natural settings. Therein lies the weakness of experimental approaches in Steffensen's view. He suggests that the tool he offers as an alternative has promise for hypothesis generation (which is not, in his opinion, a strength of experimental research), but also for making valuable observations.

In the service of understanding real, distributed, embodied cognition in the context of "sense-saturated" activities (i.e., activities involving languaging as a major part), Steffensen opts for making observations under relatively unconstrained conditions. His probatonic (lost sheep) principle is to focus on individuals (even those who, lost-sheeplike, might be excluded as outliers in a scientific sample) rather than on the groups of "participants" that are under study in experimental research. His Cognitive Event Analysis is a tool for parsing observations into kinds of activities that are relevant to understanding what is going on in the observed sets of events. He illustrates the value of the principle and the tool by using data from two problem-solving tasks.

His observations allow him to identify some possible commonalities in problem solving activities, including the occurrence of transitions between approaches to solving a problem, and event pivots, in which there is a shift to an approach that works. Activities in search of problem solution are sense-saturated (involve use of language), and embodied (with gaze, gesture, and expressions of emotion sometimes relevant to finding solutions along with talk). They lead to transitions in approaches to solutions by opening up new 
affordances for acting. He concludes (p. 12) that, "Both cases discussed in this paper illustrate how emotional, sense-saturated interactivity affects the layout of affordances and thus behaviour."

Our "but wait" here is only to remark that the virtue of Cognitive Event Analysis is also its weakness. It permits observation of highly natural human interactions, but it provides nearly unlimited degrees of freedom for interpretation of observations. Steffensen acknowledges this, but remarks that findings from experimental research also permit alternative interpretations. Not surprisingly, we persist in thinking that experiments are stronger than case studies on this score. However, we agree that the approach Steffensen takes is quite valuable for the naturalness of the interactions that provide its data and that observations from its use can lead to generation of fruitful hypotheses for further research. However, tests of those hypotheses should come, at least in part, from experimental research. We advocate the method of converging operations (e.g., Garner, Hake, \& Eriksen, 1956).

\section{The puzzle of agency}

Linell (this issue) tackles the difficult issue of understanding agency specifically in social settings involving languaging. In a review of historical approaches to agency in this kind of context, he notes that, in approaches to language itself that focused on "langue" (Saussure, 1916/1964) or "competence" (e.g., Chomsky, 1965), the issue does not arise, because actual public uses of language are set aside. Agency does arise in psycholinguistic studies, for example of language production (e.g., Levelt, Meyer, \& Roelofs, 1999). In these approaches, the agent, the individual doing the choosing, is clearly the speaker, who is, of course constrained by the language system to package his/her intended message in 
particular ways. But the speaker has the intention to communicate something to someone, and has some choice in how to put together an utterance to realize that intention.

More surprising and more interesting ideas of agency arise from approaches in which languaging is central. In these approaches, interlocutors are often engaged in joint "projects" (e.g., Clark, 1996), and research shows that, at many linguistic and bodily levels of description, they entrain to one another and coordinate with one another (e.g., Pickering \& Garrod, 2013; but see Mills, 2014, for a more comprehensive perspective). For example, they borrow one another's words and syntactic structures, and they entrain posturally. Of course, these borrowings and entrainments are not themselves signs of agency. But they are indications that interlocutors have formed a system that transcends the boundaries of the individuals' bodies. Agency, then, becomes a characteristic of the larger system, which exhibits "participatory agency":

Participatory agency means that whatever the individual creates on her own initiative, this is always embedded within constraints co-operatively set up by and with other(s) and by structural conditions defined by the language system and the activity types involved. (Linell, this issue, p. 13)

This is a very interesting idea, but a tricky one. We would like this specific understanding of agency in talk to be able to be generalized outside of contexts in which language is used and to know to what extent that generalized idea is specific to humans. Linell's answer seems to be the agency he has in mind is special to humans.. He writes: [V]alues and the situated meanings created in human interactions and civilisations, are not so immaterial, mental or spiritual as we have oftentimes been told, but....[h]aving a mind is to have a sense-making ability, and this is what 
created the human ecological niche, what makes us human. (Linell, this issue, $p$. 11)

But wait...Not "so immaterial" or not immaterial at all? And is having a mind special to humans?

\section{An ecology of language enriched}

Ecological psychology, as pioneered by Gibson (e.g., 1966; 1979) and developed substantially by others (e.g., Marsh, Richardson, Baron, \& Schmidt, 2006; Reed, 1996; Turvey, 1990; Warren, 2006) has contributed importantly to an understanding of animals' life in their econiche. It has offered valuable theoretical and methodological insights and tools for understanding perceptually-guided, and sometimes social- and value-guided (e.g., Hodges, 2009; 2014) action. Among the insights are ideas that "invariants" in informational media such as reflected light and acoustic signals that animals intercept permit "direct perception" of the ecological niche (that is, perception unmediated either by inferencing or by internal representations of the world), and ideas that "affordances" (possibilities for action) constitute the most significant perceivables. Other important insights and methodological tools have been provided to ecologists by dynamical systems theory, which has enriched understanding of coordinated action and of its coupling to perception and the coupling of perceiver-actors one to the other. Despite these achievements, the ecological approach has proven challenging to develop so that it can encompass language use. Two papers in the special issue offer exciting insights on how that extension might be conceptualized. These are papers by Rączaszek-Leonardi (this issue) and by Harvey and Cowley (this issue). 
Rączaszek-Leonardi (this issue) suggests that something important is missing from ecological theory. Its exclusive focus on the dynamics of living systems cannot elucidate the ability of some of them to use language. In particular, she suggests, the ecological approach requires enrichment from Pattee's (e.g., 1969) view of how symbols (or, as RączaszekLeonardi prefers, "informational structures") can arise in the form of replicable constraints on the dynamics of some physical systems.

As Rączaszek-Leonardi explains, for Pattee, the emergence of informational structures in a physical system is not unique to language. DNA constitutes another example, among others. In the case of DNA, the informational function it serves emerges in natural selection. In the case of language, some of its emergence may be explained in that way; but language continues to grow and evolve in shorter, generational time scales as well. What emerges in systems such as language-using humans and DNA are selective and replicable constraints on the dynamics of living systems. The constraints reduce the degrees of freedom of the system; that is, they restrict how physical laws can manifest themselves in the systems by serving as boundary conditions on their functioning. This restriction creates new macroscopic order in the systems, the "symbols" or informational structures. Because physical law provides a complete description of systems, Pattee (e.g., 1972) refers to this macroscopic level as an "alternative description" of the system.

As Rączaszek-Leonardi notes, the existence and functioning of the selective constraints reflect their historical emergence, that is, they reflect forces on a system whose origins are not obvious in the here and now, but are crucial for the system's present functioning. This understanding helps to make the effectiveness of language use "nonmagical." 
To us, Harvey and Cowley (this issue) tell a similar story. (However, see their footnote 6 for distinctions they see between their perspective and that of RączaszekLeonardi.) The aim of their paper is to replace the idea of common ground that has currency in representationalist ideas of language. In those approaches, common ground between interlocutors is information represented in their minds that is shared by them and that, characteristically, grows over the course of a communicative interaction in the service of moving a joint project forward (e.g., Clark, 1996). Common ground permits interlocutors to communicate.

The approach of Harvey and Cowley, in contrast, emphasizes the embeddedness of interlocutors and their utterances in social settings in which they are in coordinative relationships that can be understood in terms of within- and between-person synergies Some of the between-person sharing that is expressed as internally represented common ground in some accounts, instead is available to all participants in ongoing coordinative events. (See their example of the cutting board.) As the authors remark:, "Speaking and hearing are multilevel coordinations, not based primarily on the said or the known." (Harvey \& Cowley, this issue, p. 6).

However, characterization of contextualized talk in terms of coordination and synergies in a particular social setting does not capture the special nature of language use. In particular, utterances have significance for interlocutors beyond their articulatory and acoustic manifestations. Listeners' appreciation of their further significance depends on personal history, a history of embeddedness in events at slower times scales than those of an immediate social event, and encompassing communities of people. In this larger context, "wordings" (token occurrences of words) have conventional (reproduced; 
Millikan, 2003) usages that a community member can come to recognize. Learning this is learning to take a "language stance," that is learning to see the ongoing articulatory activities of a speaker as something other than mere articulatory activities (more or less as one can learn to see drawing of a tree as more than a collection of lines on a page, indeed to see that it is a drawing of a tree).

Articulatory activity that plays out over seconds and tens of milliseconds is embedded in events, structured by wordings that play out over minutes and hours (e.g., conversations, daily tasks), and in ontogenetic and historical changes that are completed over years and generations (e.g., the creation and maintenance of interpersonal relationships, identity development, and linguistic change). While interaction is lived, its dynamics are constrained by patterns that unfold in longertimescales. (Harvey \& Cowley, this issue, p. 7)

We find the ideas of Rączaszek-Leonardi and of Harvey and Cowley very exciting in many ways. One important way is that they offer valuable insights into how language can serve the functions that it does in the lives of humans without being supposed to be internally represented and without people being supposed to communicate by exchanging mental contents. Relatedly, in both accounts, languaging is embodied and fully embedded in the coordinative activities of social groups. In both accounts, languaging is a kind of coordinated, between-person activity that dynamical systems approaches to action have helped to illuminate. But in both accounts, dynamics is not enough. For RączaszekLeonardi, there is an alternative description of dynamical systems that encompasses language-using individuals, communities of them, and their econiche. The alternative description captures the informational structures that have emerged from relatively 
coarse-grained, slow-time scale constraints on the system. For Harvey and Cowley, access to that aspect of dynamical systems is achieved by people taking a language stance. We wonder if these two ideas, of alternative descriptions that some dynamical systems in fact embody, and of taking a language stance are not closely related, and even reconcilable, with the former a more general idea than the latter.

It is notable that both Rączaszek-Leonardi and Harvey and Cowley find it important to show how languaging behaviors can emerge in development. Children must come to participate in a multi-tiered, multi-time scaled set of events in which utterances can be "information structures. " Rączaszek-Leonardi discusses the emergence of language use in ontogeny to show how, even ontogenetically, activities reflecting the informational structures of language can emerge from social interaction of infants with individuals whose actions already embody those informational structures. Harvey and Cowley emphasize emergence of languaging skills initially from inter-bodily coordinations between infants and caretakers, who mutually entrain. In their understanding, joint attention between child and caretaker helps the child to see that utterances are not just patterns in vocalizations; they are utterances of something. We suspect that these insights from Rączaszek-Leonardi and from Harvey and Cowley are on a track that will foster an expansion of the explanatory scope of ecological psychology to language.

\section{Concluding comments}

These are exciting times for research on language, which is beginning to take its rightful place in the human econiche, embedded in the social, coordinative contexts in 
which it serves unique and important functions. The contributions to this special issue offer valuable tools (Cognitve Event Analysis, dynamical systems analyses) and valuable theoretical perspectives on language that we expect will foster development of new understandings of language and its roles in the social lives of humans and new forwardmoving research programs. 


\section{Author Note}

The conference that hosted presentations represented in this issue (Finding Common Ground: Social, ecological and cognitive perspectives on language use, University of Connecticut, Storrs, CT, June 12-14, 2014) was supported by the National Science Foundation grant SES-1352717, The Research Foundation of the University of Connecticut, and the Department of Psychology, University of Connecticut. We extend our thanks for that support and to all conference presenters and participants.

\section{References}

Bickhard, M. H. (2009). The interactivist model. Synthese 166, 547-591.

Chomsky, N. (1965). Aspects of the theory of syntax. Cambridge, MA: MIT Press.

Chomsky, N. (2011). Language and other cognitive systems. What is special about language? Language Learning and Development, 7, 263-278.

Clark, H. H. (1996). Using language. Cambridge: Cambridge University Press.

Dell, G. S. (1986). A spreading-activation theory of retrieval in sentence production. Psychological Review, 93, 283-321.

Frost, R. (2012). Towards a universal model of reading. Behavoral and Brain Science, $35,263-279$.

Garner, W. R., Hake, H. W., \& Eriksen, C. W. (1956). Operationism and the concept of perception. Psychological Review, 63, 149.

Gibson, J. J. (1966). The senses considered as perceptual systems. Boston: Houghton-Mifflin. Gibson, J. J. (1979). The ecological approach to visual perception. Boston: Houghton Mifflin. Harris, R. (1981). The language myth. London: Duckworth. 
Harvey, M. \& Cowley, S. J. (this issue). The illusion of common ground. New Ideas in Psychology.

Hodges, B. (2009). Ecological pragmatics: Values, dialogic arrays, complexity and caring. Pragmatics and Cognition, 17, 628-652.

Hodges, B. (2014). Rethinking conformity and imitation: Divergence, convergence, and social understanding. Frontiers in Psychology, 5

Hodges, B. \& Fowler, C. A. (2015). Fields, particles, and waves; Finding common ground in understanding language as a public activity. Ecololgical Psychology, 27, 175-189.

Ingold, T. (2000). The perception of the environment: Essays on livelihood, dwelling, and skill. London: Routledge.

Kitchener, R.F. (2006). Genetic epistemology: naturalistic epistemology vs. normative epistemology. Norms in Human Development (L. Smith and J. Vonèche, Eds.) Cambridge University Press: Cambridge, U.K.

Kravchenko, A. V. (this issue). Language as human ecology: a new agenda for linguistic education. New Ideas in Psychology.

Levelt, W. J., Roelofs, A., \& Meyer, A. S. (1999). A theory of lexical access in speech production. Behavioral and brain sciences, 22, 1-38.

Linell. P. (this issue). On agency in situated languaging: Participatory agency and competing approaches. New Ideas in Psychology.

Marsh, K. L., Richardson, M. J., Baron, R. M., \& Schmidt, R. C. (2006). Contrasting approaches to perceiving and acting with others. Ecological Psychology, 18, 1-38.

Maturana, H. (1988). Ontology of observing: The biological foundations of selfconsciousness and the physical domain of existence. R. Donaldson (Ed.) An in- 
depth exploration of the thought of Humberto Maturana, William T. Powers, and Ernst von Glasersfeld. (pp. 4-52) Felton, CA: American Society for Cybernetics. Maturana, H. (2000). The nature of the laws of nature. Systems Research and Behavioral Science, 17, 459-468.

Millikan, R. G. (2003) In defense of public language, in L. M. Antony and N. Hornstein (Eds.). Chomsky and his critics (pp. 215-237) Oxford, UK: Blackwell Publishing.

Mills, G. J. (2014). Dialogue in joint activity: Complementarity, convergence, and conventionalization. New Ideas in Psychology, 32, 158-173.

Pattee, H. H. (1969). How does a molecule become a message? In A. Lang (Ed.) Communication in Development, Developmental Biology Supplement, 3, 1-16.

Reprinted in Pattee, H. H. \& Rączaszek-Leonardi, J. Laws, language and life: Howard Pattee's classic papers on the physics of symbols with contemporary commentary. (pp. 55-67). Dordrecht: Springer.

Pattee, H. H. (1972). Laws and constraints, symbols and messages. In. C. H. Waddington (ed.). Towards a theoretical biology, 4. (pp. 248-258). Edinburgh: Edinburgh University Press. Reprinted in Pattee, H. H. \& Rączaszek-Leonardi, J. Laws, language and life: Howard Pattee's classic papers on the physics of symbols with contemporary commentary. (pp. 81-89). Dordrecht: Springer.

Pickering, M. J., \& Garrod, S. (2013). An integrated theory of language production and comprehension. Behavioral and Brain Sciences, 36, 329-347.

Rączaszek-Leonardi, J. (this issue). How does a word become a message? An illustration on a developmental time-scale. New Ideas in Psychology. 
Raggi, R., Zonca, G., Pistarini, C., Contardi, A., \& Pinna, G-D. (2002). Verb-noun double dissociation in aphasic lexical impairments: The role of word frequency and imageability. Brain and Language, 81, 432-444.

Rayner, K., Chace, K. H., Slattery, T. J., \& Ashby, J. (2006). Eye movements as reflections of comprehension processes in reading. Scientific Studies of Reading, 10, 241-255.

Reed, E. (1996). Encountering the world. New York: Oxford University Press.

Saussure, F. de (1916/1959). Course in general linguistics. C. Bally, A. Sechehaye, \& A. Riedlinger (Eds.) Translated by Wade Baskin. New York: Philosophical Library.

Steffensen, S. V. (this issue). Cognitive probatonics: Towards an ecological psychology of cognitive particulars. New Ideas in Psychology.

Taylor, T. J. (this issue). Folk-linguistic fictions and the explananda of the language sciences. New Ideas in Psychology.

Turvey, M. T. (1990). Coordination. American Psychologist, 45, 938-953.

Wallot, S. (this issue). On the principal limitations of mechanistic theories of natural language: The case of reading, New Ideas in Psychology.

Warren, W. H. (2006). The dynamics of perception and action. Psychological Review, 113, 358-389.

Webber, C. L., \& Zbilut, J. P. (1994). Dynamical assessment of physiological systems and states using recurrence plot strategies. Journal of Applied Physiology, 76, 965-973.

Wittgenstein, L. (1953/2010). Philosophical Investigations. Hoboken, NJ: Wiley- 
Blackwell. 